ORIGINAL ARTICLE

AFRICAN JOURNAL OF CLINICAL AND EXPERIMENTAL MICROBIOLOGY JANUARY 2010

ISBN 1595-689X VOL 11(1)

AJCEM/2008146/21009

-http://www.ajol.info/journals/ajcem

COPYRIGHT 2010

AFR. J. CLN. EXPER. MICROBIOL 11(1): 129-136

\title{
SOCIO-DEMOGRAPHIC CHARACTERISTICS OF ADULTS SCREENED FOR HIV/AIDS IN A RURAL COMMUNITY IN BENUE STATE, NIGERIA
}

**Odimayo, M.S., *Adediran, S.O. and *Araoye, M.A. **Department of Microbiology \& Parasitology, And ${ }^{*}$ Department Of Medicine, College of Health Sciences, Benue State University, Makurdi

Correspondence: **DR ODIMAYO, M.S. E-mail: simideledimayo@yahoo.com

\section{Running title: HIV/AIDS socio-demographic characteristics}

\begin{abstract}
Background: Benue state has been considered among the 'hot zones' for HIV/AIDS in Nigeria with a prevalence rate of 9.3 among adults aged 15 to 45 years. Yet, there is paucity of information on the socio-demographic factors associated with this level of prevalence. We hereby report the prevalence and socio-demographic factors associated with HIV among adults in Abwa-Mbagene, Benue state, Nigeria.

Methods: Adults in Abwa-Mbagene community who accepted to participate between 9th and 24th of August 2007 were recruited. After counselling, screening was done using 'Determine HIV' kit.

Results: 153 subjects (74 males and 79 females) were recruited. Their age ranges from 15 to 60 years (Mean: 26.2years). Fourty-two (27.5\%) consisting of $12(16.2 \%)$ males and $30(38 \%)$ females were positive for HIV (male to female ratio, 2:5). The prevalence of HIV was higher among the divorcees $(50 \%)$; those whose level of education was primary school $(41.3 \%)$ and below and; farmers $(60 \%)$. Majority (96\%) knows AIDS exists, 85\% are informed on mode and prevention of HIV transmission. Cases of AIDS deaths, unprotected casual sex, blood transfusion with unscreened blood and polygamy are common in the community. The single most important cultural factors in HIV transmission identified is indulgence in night parties, which increased the rate of unprotected casual sex.

Conclusion: This community represents a high HIV/AIDS prevalence spot in Benue State, Nigeria. There is therefore the need for the establishment of HIV Counselling and Testing (HCT), Prevention of Mother-To-Child Transmission (PMTCT), save blood and antiretroviral treatment services in the community. Vocational centers to engage single women and improve their financial state will boost preventive strategies. Finally, partnership with community leaders towards discouraging night parties will reduce the prevalence of HIV in the community.

Index words: Factors, prevalence, prevention, transmission.
\end{abstract}

\section{Introduction}

The AIDS epidemic continues to spread at an alarming rate all over the world. In 2006 alone, 4.3 million people were infected with HIV. Despite new advancement in the availability of HIV treatment in developing countries, 2.9 million people died from AIDS in 20061,2.
This is the highest number reported for a single year since the beginning of the pandemic. Sub-Sahara Africa is the worst affected regions and 59\% of those infected were women (1-3). In this region, where resources and aids are poor and access to health care and new treatment is limited, the vast majority (72\%) of death from 
$\mathrm{HIV} / \mathrm{AIDS}$ is seen and AIDS is now a leading cause of death between the ages 15-59 years (1). In Nigeria, AIDS cases have been reported ranging from $1.4 \%$ to $42.7 \%$ in different states of the federation with majority of cases in their prime of life (4-10). The current national average prevalence of HIV/AIDS has been found to be $3.9 \%$ (3). Considering a national population figure of 160 million and at an average prevalence of $3.9 \%$, over 6 million Nigerians may be under varied burden of HIV infection. However, the prevalence varies across states and different subgroups within Nigeria (4-12). Benue state has been found to be among the highest zones of HIV/AIDS in Nigeria, with prevalence rate of 9.3 (13). Yet, there is paucity of information on the sociodemographic factors responsible for this level of prevalence from this environment. Jegede $^{14}$ found that the context of the prevalence of cultural heterosexual relationship such as early marriage, virginity, son preference, patriarchy, widowhood and inheritance practice, extramarital and premarital sexual behaviours has negative influence on sexual behaviours and impact negatively on HIV/AIDS control. Akanni \& Erhabor

(6) found that absence of formal education, history of alcoholism, drug use, multiple sexual partners and age of first debut, are independent risk factors in adolescents HIV infection in Port Harcourt. Jegede related inadequate knowledge of the cultural context of transmission of HIV/AIDS to high level of HIV infection despite various preventive measures (14). Hence the need for more specificity with regards to different cultural and social groups rather than the current generalized 'ABC' mode of prevention.

A major factor in the control of AIDS is individual and community knowledge of HIV status through voluntary counseling and testing and the number of people willing to undergo HIV counseling and testing is higher when the test is free and treatment programme is available (15-17). This is because the poor socioeconomic factors which reduce individual willingness to pay for the test on one hand and the understanding that in the absence of life saving medicines, an HIV/AIDS diagnosis for most people may mean a notification of early death $(15,16)$. Regularly available and affordable voluntary counseling and testing usually help people to know their HIV status and affected patients can benefit from the various antiretroviral treatment programs in the country. Community Involvement in counseling and testing helps them to participate in HIV awareness and prevention activities thereby protecting their community against HIV/AIDS.

The aim of this study is to support individuals and the community of Abwa in Buruku Local Government, Benue state, Nigeria in the determination of their HIV status, determine the socio-demographic factors related to HIV/AIDS transmission 
in the community, with the intention of applying our findings in the control of HIV/AIDS transmission specifically in Abwa community and Nigeria in general.

We hereby report the prevalence of HIV/AIDS and the sociodemographic Characteristics related to HIV/AIDS transmission among adults screened for HIV/AIDS in Abwa community, Benue state, Nigeria.

\section{Methods}

This study was conducted between 9th and 24th of August 2007 in Abwa, Buruku local government, located about $110 \mathrm{~km}$ east of Markurdi, the capital city of Benue state. The community is located along a major road leading to Taraba state on the left, Cross river state on the right and straight to the Cameroon border. The community consists of four quarters, 622 compounds and about 10,000 people.

Ethical approval was given by the Ethical Review Committee of the college of Health Sciences, Benue State University, Makurdi. On arrival at the local government, the chairman of the local Government and other members of the council were informed of the presence of the group and the various projects to be conducted during the period. The traditional leader and members of his council were met and the mission of the group was discussed with them in detail. We were accepted by the community and the people promised full support and cooperation.
Randomly selected individual within reproductive age group who accepted to participate was recruited into the study. Participants were sent for counseling and HIV testing. The counseling was done following a format in the questionnaire (designed by the authors), which included bio data, marital status, previous risk factors, knowledge of the respondent on the various preventive measures, cultural factors in the locality perceived by respondent to be responsible for HIV transmission and their perception and reactions to individual with HIV/AIDS among other questions.

Sample size was determined using the formula: $\mathrm{n}=\mathrm{Z}^{2} \mathrm{pq} / \mathrm{d}^{2}$

$$
\begin{aligned}
& \text { Where } \mathrm{n} \mathrm{q}=1.0-\mathrm{p} \quad \text { i.e } \quad 1.0-0.093 \\
&= 0.907 \\
& \mathrm{~d}=\text { degree of accuracy desired, }
\end{aligned}
$$

which will be set at 0.05 .

Therefore the minimum sample

size is: $\mathrm{n}=\mathrm{Z}^{2} \mathrm{pq} / \mathrm{d}^{2}$

$$
\begin{aligned}
& \mathrm{n}=(1.96)^{2}(0.093)(0.91) /(0.05)^{2} \\
& =0.3388291 / 0.0025=130
\end{aligned}
$$

$=$ the desired sample size (when population is greater than 10,000)

$Z$ = the standard normal deviate, usually set at 1.96 (or more simply at 2.0) which corresponds to the $95 \%$ confidence level. $\mathrm{P}=$ the proportion in the target population estimated to have a particular characteristic, in this study, the previous finding in this environment that shows $\mathrm{HIV} / \mathrm{AIDS}$ prevalence in Benue state as $9.3 \%$ (13) was used. 
Testing was done at no cost to the volunteers after pre test counseling using third generation ELISA kit called 'Determine HIV' produced by Abbott diagnostics. Manufacturer's manual was followed, briefly as follows: after identification of the patient, patient's finger was cleaned with $70 \%$ alcohol, using sterile lancet, a prick was made on the pulp of the thumb. The strip was opened, a drop of blood was collected on the specimen site and 2 drops of diluents were then added and the mixture was allowed to migrate to the viewing site. Interpretation was done in which red or pink band at the test and control sites was considered positive. Similar band only at the control site alone was interpreted as negative, while band occurring only at the test site was considered an invalid result.

Post test counseling was then conducted: HIV positive patients were referred to treatment centers and negative patients were advised on preventive measures against HIV/AIDS. Issues related to stigmatization and cultural practices perpetuating the disease prevalence were noted and thoroughly discussed. Towards the end of the programme, health talks were organized emphasizing the prevailing health problems in the community and the various modes of prevention. The attendance at the health talk was impressive cutting across age, occupational and sociopolitical boundaries in the community, comments and questions were properly addressed.
Results are presented in tables and figures as applicable. Comparisons were made using standard statistical methods in which categorical data were compared by Chi-Square. Conclusions and recommendations were based on scientific evidence from the results.

\section{Results}

One hundred and fifty-three subjects were recruited into the study consisting of 74 males and 79 females, age ranging from 15 to 60 years. Fourty-two (27.5\%) subjects consisting of $30(38 \%)$ females and 12 (16.2\%) males were positive giving a male to female ratio of $1: 2.5$. The mean age of positivity among males was 23.9 years while that among females was 28.5 years. The highest incidence was found among the 20-29 year age groups in both sexes. There was none positive above the age of 55years. (Table 1)

The highest number of subjects recruited into the study were the married (71), followed closely by the single, divorced and the widowed. The highest prevalence of HIV was found among the divorcees or with the history of divorce (50\%) while the lowest was among the married (22.4\%) and the difference is statistically significant. (Figure 1)

Sixty percent of the subjects recruited into the study were farmers. 22 (14.4\%) were students while civil servants were the least common group. Others, which include community workers, house wives and medical laboratory technicians represent $11.1 \%$ of the study group. The highest 
HIV prevalence was seen among farmers $(46 \%)$, while the lowest prevalence was seen among traders (16.7\%). The prevalence of the infection was significantly higher among farmers when compared with other occupational groups.

\section{(Table 2)}

FIGURE 1: MARITAL STATUS OF SUBJECTS

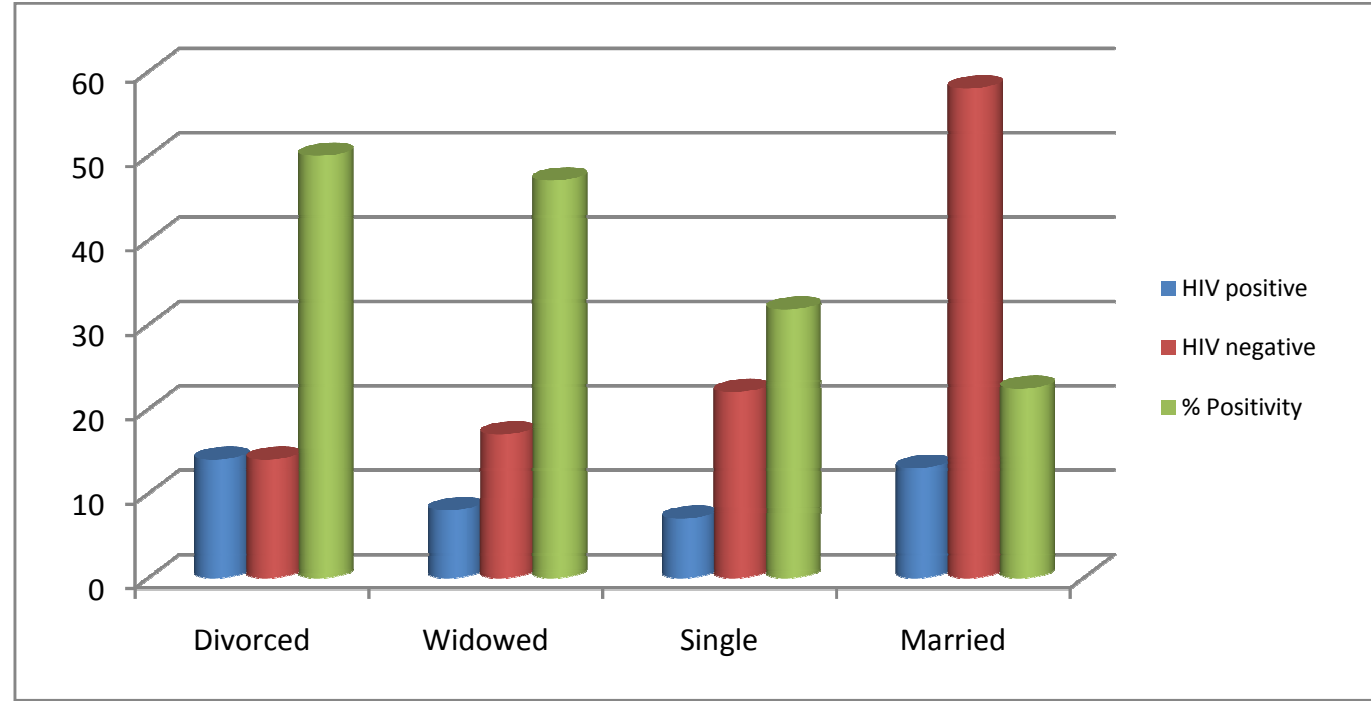

Married versus divorced $x^{2}=10.27 ; p$-value $<0.05$

Sixty-nine $(45.1 \%)$ of the subjects had secondary school as their highest level of education while $14(9.1 \%)$ had postsecondary school education, which were National certificate in Education (NCE), School of health, or other diploma courses. The highest number of HIV prevalence was found among subjects with the lowest level of education, that is; primary school $(41.3 \%)$, followed by those with no formal education (29.2\%). HIV was least prevalent among those with post secondary education (18.8\%). (Figure 2). Over $96 \%$ of the subjects believed HIV/AIDS exists. $85.6 \%$ were well informed about the mode of transmission and preventive measures. Majority (65.4\%) had seen one or more HIV/ AIDS patients the neighbourhood and $60.8 \%$ had seen one or more people die of AIDS in the last 6 months. Only $9.8 \%$ of the subjects would discriminate against HIV/AIDS patients (Figure 3). 
FIGURE 2: LEVEL OF EDUCATION AMONG SUBJECTS

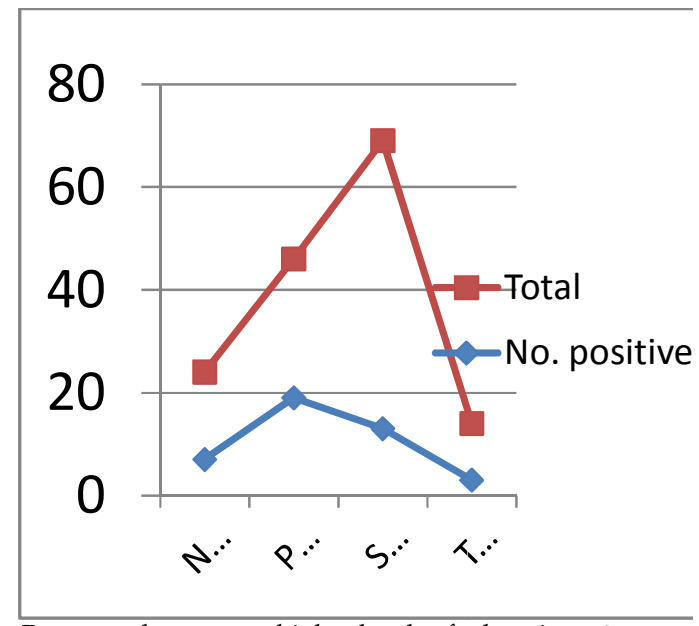

Pre-secondary versus higher levels of education: $\mathrm{x}^{2}=$ 12.17; p-value $<0.5$

FIGURE 3: KNOWLEDGE AND PERCEPTION OF SUBJECTS ON HIV/AIDS

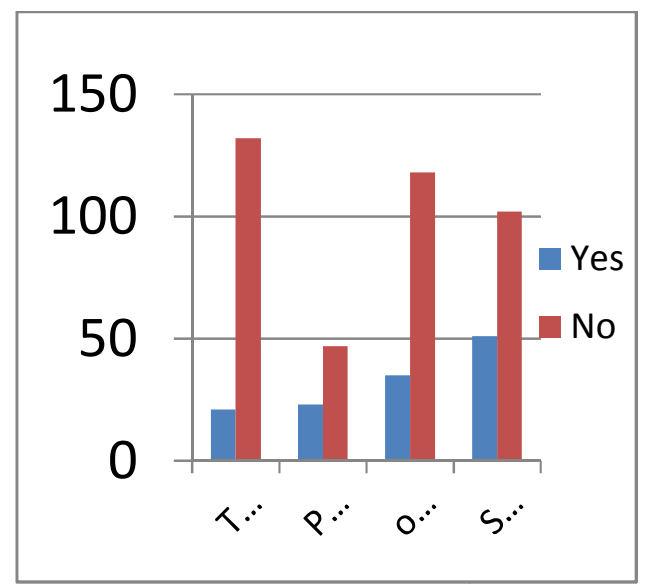

FIGURE 4: PREVIOUS EXPOSURE TO HIV/AIDS RISK FACTORS

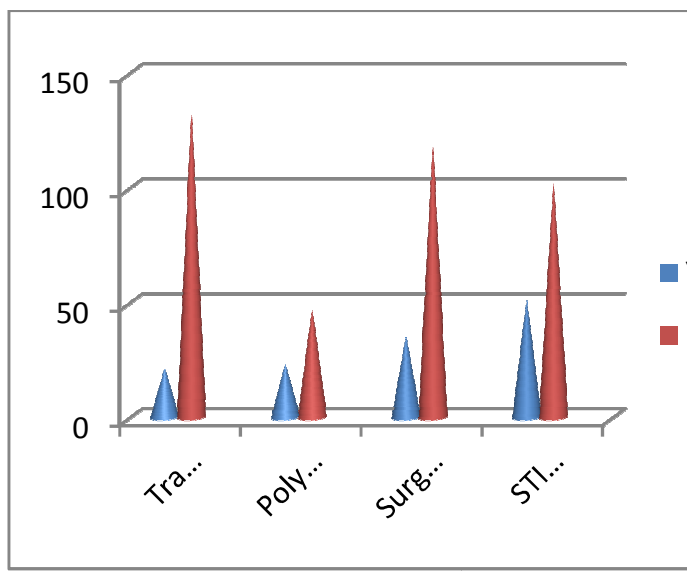

Fourteen percent of subjects had blood transfusion at least once in their life time. $33 \%$ had previous sexually transmitted infection or are practicing polygamy, and $23 \%$ had previous surgical operation, which ranged from bilateral tubal ligation to total abdominal hysterectomy (Figure 4). Over $90 \%$ of the subjects believed that a major cultural factor in HIV transmission in the environment is unprotected sex following night parties usually during burial wake keeping.

\section{Discussion}

The $27.5 \%$ of HIV positivity among subjects seen in this study is higher than the average reported earlier in Benue $\operatorname{state}^{13}(9.3 \%)$, from Kano $(1.44 \% ; 3.8 \%)$ in 20065 , $2003^{7}$ respectively, from Calabar $(2.7 \%)$ in 2003 (11) and from Abeokuta $(14.7 \%)$ in 2007 (8). It is however lower than that from Port Harcourt $42.7 \%$ in $2005^{6}$ and comparable with the finding of Bakare et al (12) where $34.3 \%$ HIV prevalence was seen among commercial sex workers (2003). The rate found in this study is significantly higher than the national $(3.9 \%)$ and state $(9.3 \%)$ average prevalence $(3,13)$. This calls for concern as this type of pockets of high prevalence can adversely militate against the various national and international control efforts. 
TABLE 1: AGE AND SEX DISTRIBUTION VERSUS HIV STATUS OF SUBJECTS

\begin{tabular}{|l|cc|cc|cc|}
\hline $\begin{array}{l}\text { Age group } \\
\text { (years) }\end{array}$ & \multicolumn{2}{|c|}{ HIV positive } & \multicolumn{2}{|c|}{ HIV negative } & \multicolumn{2}{|c|}{ Total } \\
\hline$<15$ & None & None & None & None & None & None \\
\hline $15-19$ & 2 & 3 & 9 & 6 & 11 & 9 \\
\hline $20-24$ & 4 & 10 & 9 & 7 & 13 & 17 \\
\hline $25-29$ & 2 & 7 & 10 & 8 & 12 & 15 \\
\hline $30-34$ & 1 & 3 & 8 & 10 & 9 & 13 \\
\hline $35-39$ & 1 & 3 & 8 & 4 & 9 & 7 \\
\hline $40-44$ & 1 & 2 & 8 & 5 & 9 & 7 \\
\hline $45-49$ & - & 1 & 4 & 3 & 5 & 4 \\
\hline $50-55$ & 1 & 1 & 4 & 3 & 4 & 4 \\
\hline$>55$ & Nil & nil & 2 & 3 & 2 & 3 \\
\hline Total & $\mathbf{1 2}$ & $\mathbf{3 0}$ & $\mathbf{6 2}$ & $\mathbf{4 9}$ & $\mathbf{7 4}$ & $\mathbf{7 9}$ \\
\hline
\end{tabular}

Average Prevalence rate $=27.5 \%$; mean age; male $=23.9$ years; female $=28.5$ years; male to female positivity ratio $=1: 2.5$

TABLE 2: OCCUPATIONAL ENGAGEMENT AMONG SUBJECTS

$\begin{array}{lccc}\text { Occupation } & \text { No positive } & \text { No. negative } & \text { Total (\%) } \\ \text { Farmers } & 29 & 63 & 92(60) \\ \text { Students } & 4 & 18 & 22(14.4) \\ \text { Traders } & 2 & 12 & 14(9.2) \\ \text { Civil servants } & 2 & 6 & 8(5.2) \\ \text { Others } & 5 & 12 & 17(11.1) \\ \text { Total } & 42 & 111 & 153(100)\end{array}$

Farmers versus other groups $\mathrm{X}^{2}=3.840 ; \mathrm{p}$-value $=>0.05$

The male to female positivity ratio of 2:5 seen in this study is similar to other findings ${ }^{6,18}$ in which women have been found to be two to four times more vulnerable to HIV infection than men during unprotected sexual intercourse because of the larger surface area exposed to contact. Besides, the female is the recipient of semen and is prone to micro trauma during sexual intercourse.

HIV was significantly higher among subjects who were previously or currently divorced in this study. This prevalence is followed closely by the widowed, showing that single women are more vulnerable to HIV infection than married ones. This may be accounted for by absence of 
family cover, which could shield or restrain them from multiplicity of sexual partners. Financial demand, efforts to re-marry, sexual assault and unusual freedom, among others, may be responsible for the high prevalence seen among single women in this study. Further study is needed to determine the relative importance of these factors in the higher prevalence of HIV/AIDS among unmarried females in this environment.

The importance of financial factors in HIV transmission is further buttressed by highest prevalence of the infection among farmers in this study. Efforts at stress reduction resulting from unattained goals may facilitate trading of sex for money and may be a major factor among this group of subjects. Ability to assert self and relative financial independence may be important factors in lowering the rate of HIV prevalence seen among traders and civil servants in this study.

Majority of the HIV positive subjects in this study were individuals whose highest level of education was primary school and below. There was significant difference between subjects with no secondary schools education and the more educated ones, factors responsible may be related to their low understanding of the knowledge acquired by subjects on HIV/AIDS and their willingness and ability to utilize such information in taking informed decision related to HIV/AIDS preventions. This is because the majority of the subjects know that AIDS exists. Though only a few have the consciousness that transfusion with HIV infected blood may be a major factor in HIV transmission, most are well informed about other modes of transmission and prevention of HIV/AIDS. Poverty and emotional instability may explain why the people were still involved in the various risk factors after seeing many AIDS patients and even deaths. Issue of self denial and the feeling of 'it can only affect them, not me', 'we are many', 'man must die of something' are among some personal feelings noted from interaction with infected patients. Worthy of note among the group of HIV positive individual is that females who are less exposed to the various risk factors associated with HIV are emotionally more disturbed about their HIV status as reflected by the usual emotional outbursts associated with the realization of their HIV positivity.

Majority of the subjects in this study will not discriminate against AIDS patients, showing that stigmatization is not a major issue in this environment. The care for the sick among the family members in terms of show of love and concern demonstrated by the people is obviously impressive. Varied percentage of the study population has been exposed to risk factors associated with HIV transmission such as blood transfusion, previous operation, previous history of sexually transmitted infections (especially purulent urethral discharge among men and lower back pain among women) and polygamy. Of major concern and worthy of note is the interest in surgical operation by the people. Yet, there are only a few numbers of qualified staff for such procedures in the 
environment. From our personal relationship with some of the health workers, it was found that community members prefer unscreened blood for transfusion basically for financial reasons. Little wonder that only a few of our subjects in this study will consider blood transfusion with HIV infected blood as a major risk factor in HIV transmission. Thus, involvement of the community in partnership for HIV/ AIDS control is needed ${ }^{19}$.

We therefore conclude that HIV infection is a major health issue in the community, especially among the single women. The level of awareness of the disease is high among the people but their understanding of unscreened blood in HIV transmission is low. Majority engage in the various risk factors such as unprotected casual sex, which predisposes them to sexually transmitted infections, blood transfusion with unscreened blood and polygamy despite their awareness of the associated risks for HIV infection. The single most important cultural factor identified is night parties. This has increased the rate of unprotected casual sex.

We hereby recommend that Voluntary Counseling and Testing (VCT), Prevention of Mother to Child Transmission (PMTCT), provision of save blood and antiretroviral treatment centers are urgently needed in Abwa community to help control the tide of the HIV/AIDS rampage. Vocational centres are paramount to engage the single women and improve the financial state of the populace. Finally, there is urgent need to engage the community leaders in cultural practices that will lead to the discontinuation of night parties.

\section{Acknowledgements}

We hereby appreciate Benue State University's administration for support for the COBES programme and the community for their cooperation towards the success of the work. We specially appreciate Professor Akase Paul Sokaa and Honorable Gideon Dodo for their financial supports and encouragement.

\section{References}

1 WHO project: ICP BCT 001, laboratory support to HIV diagnosis and monitoring of Antiretroviral Therapy; Report of a regional workshop pune, India 27th - 30th July 2004, $1,10,11$

2 www.unaids.org/en/HIV\%5Fdata/epi2006

3 UNAIDS/WHO 2007 Report on the global AIDS epidemics

4 Olaleye DO. The fingerprint of a monster; Message from the death to the living. Inaugural lecture, University of Ibadan. 2003.

5 Nwokedi EE, Aminu A, Taura AI, Bukar DA. HIV seroprevalence rates among prospective service personel in a Nigerian Security Facility. African Journal of Clinical and Experimental Microbiology. 2006; 7 (2): 101-105.

6 Akanni CI, Erhabor O. Socio-demographic Characteristics of young adults screened for HIV in a Tertiary Health Centre in Southern Nigeria. Highland Medical Research Journal. 2005; 3(1): 24-30. 
7 Imoru M, Eke C, Adegoke A. Prevalence of Hepatitis-B surface Antigen (HBsAg), Hepatitis C Virus (HCV) and Human Immunodeficiency Virus (HIV) among Blood Donors in Kano State, Nigeria. Journal of Medical Laboratory Science. 2003; 12 (2): 5255.

8 Ojo DA, Mafiana CF, Adeniran-Sonola A. Prevalence of Mycobacterium tuberculosis and Human Immunodefifiency Virus infections in Abeokuta, Ogun State, Nigeria. Journal of Parasitology. 2007; 28(1): 39-43.

9 Nneli R0, Ebguonu VN. Seroprevalence of HIV Infection among Orthopaedic and Plastic Surgery Patients in Enugu, NigeriaA six month Study. Nigerian Journal of Physiological Sciences. 2004; 19 (1\&2): 98-101.

10 Jeremial ZA, Okon IA, Jeremial TA. Seroprevalence of HIV and Frequencies of Haemoglobin genotype, ABO and Rh Blood groups among premarital couples in Port Harcourt, Nigeria. South African Family Practice. 2007; 49(2): 15.

11 Ekure EN, Etuk SJ. Factors Influencing HIV Seroprevalence rate among Pregnant Women in Calabar, Nigeria. Global Journal of Medical Sciences. 2003; 2(2): 91-95.

12 Bakare RA, Oni AA, Umar US, Shokunmbi WA, Fayemiwo SA. Seroprevalence of HIV Infection among Commercial sex workers in
Ibadan, Nigeria. Trop J Obstet Gynaecol. 2003; 20: $12-15$.

13 Thea Hilhorst, Marti Kam Liere, Korrie de Konig. Impact of AIDS on rural livelihood in Benue State, Nigera. Sahara J (Journal of Social Aspect of HIV/AIDS Research Alliance). 2001; 3: 3-6

14 Jegede AS. A qualititative Investigation of cultural context of HIV transmission in two selected Yoruba communities of Southwestern Nigeria. Nigeria Journal of Genitourinary Medicine. 2005; 5(1\&2): 16-24

15 Kristen Jill Kresge. Testing, Testing, 1, 2, 3. International AIDS Vaccine Research. 2006; 10: 1-5 www.iavreport.org

16 Akande AA, Akande TM, Odimayo MS. Perception and willingness of clinical Medical students to undergo HIV screening. Nigerian Journal of Genito-urinary medicine.2004; $3 \& 4$ (1 \& 2): 18-21

17 Akande TM. Willingness of Health workers to undergo HIV screening. Nig. Qtr. J. Hospital medicine. 1999; 90: 303 - 306.

18 Musa YB, Adisa AO, Adediran IA, Durosimi MA. Ortorlaryngologic Associated features of HIV/ AIDS

Patients in Ile-Ife, Nigeria. Nigerian Journal of Clinical Practice. 2004; 7: 69-73 